\title{
To the question of improvement the normative methodology for calculating the frost resistance of a road structure
}

\author{
$G L \mathrm{Kagan}^{1, *}, V A$ Shorin $^{1}$, and $A Y$ Velsovskij $^{1}$ \\ ${ }^{1}$ Department of Highways, Vologda State University, Lenina str. 15, 160000, Russia
}

\begin{abstract}
The paper discusses the negative impact of heaving soil during freezing of a road structure, including heaving formation. The provisions of normative methodology for testing the road structure for frost resistance are considered. The results of indirect and laboratory tests for determining the soil group by the degree of heaving are analyzed. The validity of influence of natural factors on frost heaving is considered. Proposals for improving the normative methodology are put forward.
\end{abstract}

\section{Introduction}

The natural and climatic conditions of the Russian Federation are conducive to frost heave which takes place almost everywhere on its territory. Economic feasibility necessitated the use of heaving soils in road structures.

Redistribution of moisture takes place in heaving soils during their freezing. Under natural conditions, it is associated with the influx (migration) of moisture to the freezing boundary. The volume of incoming water is much larger than that the pores of freezing soil can encompass. This results in appearance of internal pressure in the freezing soil layer, causing an elevation of the frozen soil surface (heaving deformation) and an increase in humidity compared to the initial value of hundreds of percent.

Thus, the negative impact of the heaving soil used in road structures during their freezing is manifested in the following:

1. The development of uneven deformations of frost heaving of the road surface, which is one of the causes of its destruction;

2. The decrease in the strength of the road structure during spring thawing.
The mechanism of formation of heaves on roads is an example of the second negative impact. The process of heaves formation on road is caused by the fact that its construction is made mainly from heaving soils. In the spring, surface thawing of the frozen road mass, which includes pavement and subgrade working layer, begins. Prior to start of thawing, the road structure is a frozen massif, the thickness of which corresponds to the maximum freezing depth. According to the terms of use there is no snow cover on the road surface as opposite to that on roadsides and slopes. Therefore, the initial thawing period is characterized by a bowl of thawed soil formed under the road surface. Due to the increased humidity, this soil is usually in a free-flowing state. At the initial stage of thawing, there are no ways to squeeze out water, and that excludes the possibility of consolidation of thawed soil. This leads to a significant decrease in the strength of pavement, which in this case will be determined only by the strength of pavement. The asphalt-concrete pavement is known to have low tensile and bending properties.

A plate on an elastic Winkler foundation can serve as a design scheme for the operation of a pavement on a weak foundation. The loading of this system by loads from the vehicles wheels for a road with two lanes is

a)

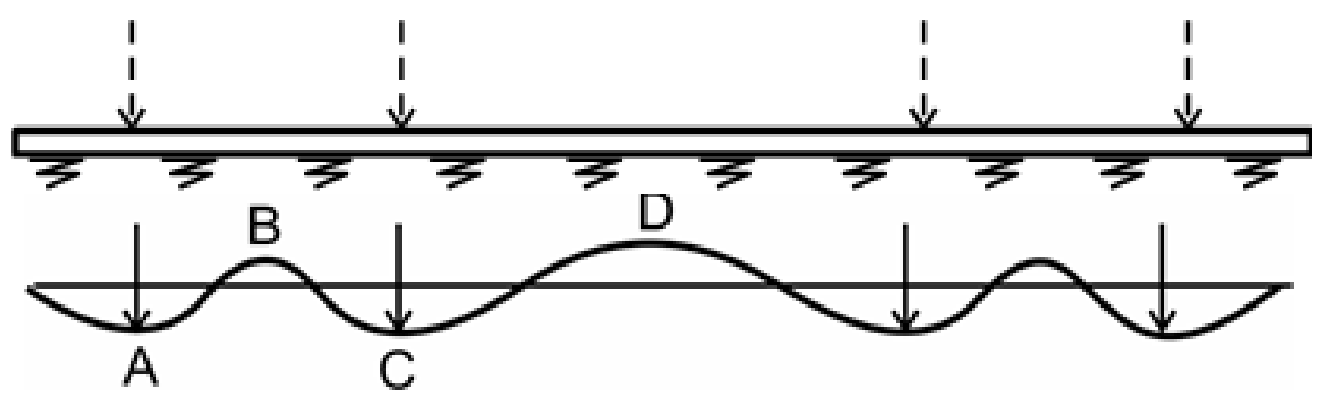

Fig. 1. The scheme of elastic axis of road pavement during formation of heaves on the road.

\footnotetext{
* Corresponding author: $\underline{\mathrm{v} 2 \mathrm{u} @ \text { yandex.ru }}$
} 
Table 1.

\begin{tabular}{|c|c|c|c|c|c|c|c|c|c|c|}
\hline \multirow{2}{*}{ No. } & \multicolumn{9}{|c|}{$\begin{array}{l}\text { Granulometric composition: partial residues in \%, } \\
\text { on sieves in } \mathrm{mm}\end{array}$} & \multirow{2}{*}{$\begin{array}{l}\text { Soil classification } \\
\text { according to } \\
\text { GOST-25100-2011 }\end{array}$} \\
\hline & $\begin{array}{c}\text { More } \\
\text { than } 10.0\end{array}$ & $5-10$ & 2.0 & 1.0 & 0.5 & 0.25 & 0.10 & 0.05 & $\begin{array}{l}\text { less than } \\
0.5\end{array}$ & \\
\hline 1 & 4.5 & 3.8 & 3.2 & 5.1 & 8.1 & 23.2 & 29.2 & 8.5 & 14.4 & Fine sand \\
\hline 2 & 0.0 & 3.3 & 2.4 & 3.9 & 7.6 & 25.6 & 38.4 & 9.2 & 9.5 & Fine sand \\
\hline 3 & 0.0 & 2.0 & 3.4 & 6.6 & 8.3 & 19.1 & 26.5 & 11.2 & 22.8 & Dust sand \\
\hline 4 & 4.6 & 6.3 & 5.7 & 7.7 & 8.6 & 17.0 & 23.9 & 9.9 & 16.4 & Dust sand \\
\hline 5 & 0.0 & 3.4 & 4.1 & 5.9 & 8.6 & 24.8 & 34.1 & 9.4 & 9.6 & Fine sand \\
\hline$\ldots$ & & & & .. & & & $\ldots$ & $\ldots$ & .. & \\
\hline 25 & 5.9 & 5.0 & 5.5 & 13.4 & 20.8 & 26.5 & 9.9 & 3.5 & 9.6 & Coarse sand \\
\hline
\end{tabular}

Table 2.

\begin{tabular}{|c|c|c|c|c|}
\hline \multirow[b]{2}{*}{ Sample No. } & \multicolumn{2}{|c|}{$\begin{array}{l}\text { Assessment according to } \\
\text { ODN 218.046-01 tables }\end{array}$} & \multicolumn{2}{|c|}{ Laboratory test results } \\
\hline & $\begin{array}{l}\text { Amount of } \\
\text { particles } \\
\mathrm{d}<0.05 \mathrm{~mm} \\
\text { in } \% \\
\end{array}$ & $\begin{array}{l}\text { Degree of heaving } \\
\text { properties }\end{array}$ & $\begin{array}{c}\text { Relative deformation } \\
\text { of frost heaving } \varepsilon_{\mathrm{fn}}, \\
\%\end{array}$ & $\begin{array}{l}\text { The degree of heaving } \\
\text { according to GOST } 25100-2011\end{array}$ \\
\hline 1 & 14.4 & Low-heaving & 9.3 & High-heaving \\
\hline 2 & 9.5 & Low-heaving & 3.0 & Low-heaving \\
\hline 3 & 22.8 & High-heaving & 9.2 & High-heaving \\
\hline 4 & 16.4 & High-heaving & 8.8 & High-heaving \\
\hline 5 & 9.6 & Low-heaving & 2.4 & Low-heaving \\
\hline$\ldots$ & 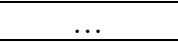 & & & \\
\hline 25 & 9.6 & Low-heaving & 7.0 & Medium-heaving \\
\hline
\end{tabular}

shown in Figure 1a. The elastic axis deformation caused by these loads is shown in Figure 1b.

It is known that the maximum tensile forces during bending occur at points where the tangent to the elastic axis coincides with the horizontal axis, i.e. at points $\mathrm{A}$, B, C, D, etc. (Figure 1b). The destructions of pavement occur in sections corresponding to these points.

To eliminate the first negative impact at the design stage, the road structure is tested for frost resistance. The methodology for these calculations is included in the existing standards [1]. We should note that the use of heaving soils in road structures is prohibited according to international standards.

The second negative impact is taken into account at the stage of operation of roads.

When heaving soil is thawed in road constructions, it is usually in a fluid state and at the same time its strength can be reduced to $80 \%$, depending on the soil type. This is a consequence of moisture migration to the freezing boundary of soil. In order to exclude the destruction of road structure in the spring, motion of vehicles with loads exceeding permissible is restricted on the motor roads of the Russian Federation. This problem and the ways to solve it are considered in more detail in [2].

The standard methodology for calculating frost resistance was developed by the Russian scientists in the seventies of the last century. The theoretical basis for it was the decision of N. A. Puzyrevsky, which was brought to practical implementation by a team of employees of the USSR Leningrad Road Research Institute (LenSoyuzDORNII) under the leadership of M. B. Korsunsky. This technique was included in the
Russian normative document Industry-Specific Construction Standards VSN 46-83 [3], published in 1985. Without significant changes, it is also used in the existing standards [2].

The soil group according to heaving properties was the initial characteristic upon implementation of this methodology. It is recommended to determine this norm characteristic during laboratory tests in accordance with the current standard. It is allowed to determine this characteristic by an indirect (approximate) method, using the physical properties of soil. Nowadays, the indirect method is most often used in the design of non-rigid road pavement.

The error of this method in comparison with laboratory tests was estimated at the Department of Highways of the Voronezh State University for several production facilities. The tests were carried out in a specialized laboratory of the University.

In 2010, a reconstructed section of one of the federal roads in the Leningrad Region was used as a source for 25 samples of sandy soils, which were taken along the highway during surveys and were tested. The particle size distribution and soil classification according to the Russian State Standard GOST 25100-2011 [4] are given in table 1.

The degree of heaving properties was assessed by indirect method according to the recommendation of the Industry Road Codes ODN 218.046-01 [1] presented in tabular form. The source data for this definition is a variety of sandy soil and the percentage of particles less than $0.05 \mathrm{~mm}$ in diameter. Comparison of results from 
indirect determination methods and laboratory test is given in table 2 .

It was shown that data on degree of soil heaving obtained by indirect method coincide with laboratory test data for8 samples of a total of 25 samples, which is $32 \%$. For a significant number of samples, the indirect method of assesment gives an unacceptable error by reducing the degree of frost heaving of soil. For example, according to this method the soil of samples Nos. 1, 6, 9, 12, 13, $15,22,23,24,25$, which make up $40 \%$ of the total, was classified as low-heaving, but according to laboratory tests it was classified as heaving, high-heaving or excessively high-heaving.

Such an error cannot be considered acceptable, especially when choosing sand soil for the installation of a frost protection layer in a road structure.

In 2010, during the construction of a pipe-profile plant being built in the village of Sheksna (Vologda Oblast) for the cold storage of finished products, the project involved the filling of non-heaving or lowheaving soil under concrete floor.

A survey of local sandy borrow pits according to the recommendations of the standards used in road construction [1] showed that two of them are suitable. In one of the pits, the soil was characterized as coarse sand containing $7.5 \%$ particles less than $0.05 \mathrm{~mm}$ in size, and in the other, it was gravelly sand containing 9.5\% particles less than $0.05 \mathrm{~mm}$ in size. Such soils, according to table 4.2 of ODN 218.046-01 [1] (indirect method of determination) are classified as low-heaving, with maximum relative deformation of frost heaving, $\varepsilon_{\mathrm{fn}}=$ $4 \%$. Further, it was required to clarify the degree of frost heaving of these soils during laboratory tests. As a result, it was found that coarse sand was classified as highheaving $\left(\varepsilon_{\mathrm{fn}}=9.3 \%\right)$, and gravelly sand was excessively high-heaving $\left(\varepsilon_{\mathrm{fn}}=12.5 \%\right)$. Later on, the filling made from this soil had to be removed.

This example also confirms the impossibility of using an indirect assessment method to determine the heaving degree of sandy soils.

Further we give an example of data comparison for the degree of heaving obtained by indirect method and by laboratory testing for clay soil. For this comparison, the soil of one of the construction sites of the Republic of Yakutia was used, for which geological engineering surveys were carried out in 2014. Testing for frost heaving was performed for 41 samples. The degree of frost heaving obtained by indirect method and by laboratory tests coincided for 14 samples (34\%). The degree of frost heaving from indirect method was underestimated for 12 samples $(29.3 \%)$ and overestimated for 15 samples $(38.7 \%)$.

The considered example shows that the use of indirect method to determine the degree of heaving of clay soil can lead to lowering of the soil group by the degree of heaving for almost not less than a third of the total number of samples. Thus, the indirect method of assessing heaving soil properties does not allow road designers to have reliable initial data when calculating road structures for frost resistance.
These indirect methods do not take into account many factors that influence the frost heaving. It is known that the composition of clay fractions in soil can change the frost heaving degree by 4-8 times, and the composition of exchange cations by 4.5 times. Identification of these factors during standard soil tests in production laboratories is not performed. The necessary reliability of evaluation of heaving soil properties can be ensured only during laboratory tests.

A significant drawback of the normative methodology is correction of deformation of frost heaving using coefficients that take into account various natural factors. The $K_{\text {ugv }}$ coefficient considers the depth of groundwater, $K_{\mathrm{pl}}$ considers the degree of compaction of the soil, $K_{\mathrm{gr}}$ considers particle size distribution, $K_{\text {nagr }}$ considers the load from the own weight of the soil, $K_{\mathrm{vl}}$ considers the estimated level of criticality. Obviously, during the development of the standards, the methodology for laboratory determination of the degree of heaving was different from the standard [5], which was issued much later. Note that tests according to the standard methodology allow determining the deformation of frost heaving for natural conditions with an accuracy of $10-15 \%$. Consider the results of more recent studies related to the influence of these factors.

The influence of groundwater level depth on the process of heaves formation of soil in the subgrade cannot be considered reasonable. The works of V.I. Fedorov $[6,7]$ issued in the mid-90s for the first time showed that water cut of soils of disturbed natural structure does not depend on the position of the groundwater horizon. The author confirms this conclusion by numerous examples from engineering practice, as well as experimental and theoretical studies carried out under his leadership at the Far East Scientific Research Design and Technological Institute for Construction (DalNIIS Institute).

One of the typical examples confirming this phenomenon was the construction of a plant in the south of Ukraine. At the construction site, groundwater was located outside the topsoil with a thickness of 17 meters composed of loess-like loams. An increase in groundwater levels was noted in the first years after the plant construction. The rise in level continued during a long break in plant work in the absence of engineering networks. For 7-8 years, the groundwater level rose by 17 meters, and the average rate of rise was 2 meters per year. It was noted that this phenomenon also occurs under buildings in which there is no water conduit and sewage system, i.e. there is no possibility of water leakage into the soil from utility networks.

One of the experiments performed by V.I. Fedorov shows a clear illustration of how much the water cut of soil changes after damage of its structure. In Khabarovsk, a pit of a 2.5 meter depth and $1 \times 2$ meter in size was excavated on a small terrace. The relief profile of the site with pit dimensions is shown in Figure 2. 


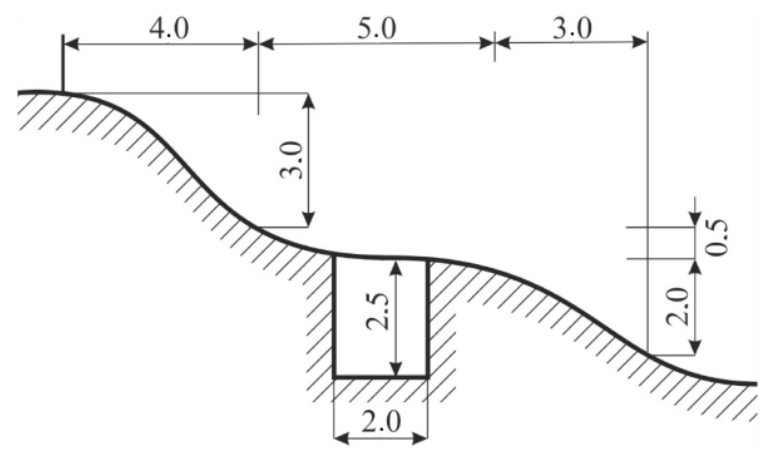

Fig. 2. The relief profile of the site with pit dimensions.

The soil of the terrace is formed by loams with a thickness of 10 to $20 \mathrm{~m}$, within which there was no groundwater. Immediately after cutting of pit, it was filled with the same soil. It was laid in separate layers with a height of $15-20 \mathrm{~cm}$ with compaction by hand tamping to a density corresponding to the density of natural soil. Over the years, observations of changes in water regime showed that both in the pit and in the adjacent massif, an increase in soil moisture was observed. Bulk soil in the pit had the highest humidity. A year later, the groundwater level was at a depth of $1.5 \mathrm{~m}$. Increased humidity in the pit was observed during the entire observation period, which was carried out for 3 years.

The given examples, as well as a number of other ones presented in works of V.I. Fedorov, allowed him to conclude that the flooding of clay soil of a disturbed structure does not depend on the position of the groundwater horizon, but is associated with an increase in its water-holding ability. He also provides a theoretical justification for this phenomenon. A similar conclusion is true for the soil pavement of road, which is formed by the soil of a disturbed natural structure.

Thus, for heaving soil of a disturbed structure, used both as a road foundation and as a material in their structures, laboratory tests for frost heave must be carried out with full water saturation of samples. In this case, it does not seem necessary to take into account the influence of coefficients $K_{\mathrm{ugv}}$ and $K_{\mathrm{vl}}$.

Consider the influence of load of road structure gravity weight on the soil in the freezing layer. The scientists of Central Research, Experimental and Design Institute for Rural Construction (CNIIEPSelstroy Institute) are the ones to perform the most comprehensive research in this area in the $80 \mathrm{~s}$ when substantiating the methodology for calculating shallow foundations. They also included the determination in natural conditions of normal forces of frost heaving, affecting the foundations in various engineering and geological conditions. Detailed information about these studies is given in [8].

The tests were carried out on 4 sites of various settlements located in the Kaluga, Vologda and Yaroslavl regions. At these sites, various types of lowdeepened and non- deepened foundations were formed.

Metal platforms were mounted along the upper edge of foundations. The loading of foundations was carried out with a calibrated load, in which concrete blocks were used. Thus, loading the foundations with various loads, allows one to establish at what value the deformation of frost heaving is excluded. This force will correspond to the resultant of normal forces of frost heaving.

The test results showed that the normal forces of frost heaving depend on many factors, including the heaving properties of soil, the freezing depth under foundations, the type of foundations, the size of sole, etc. Frost heaving forces can reach $3 \mathrm{MPa}$ or more depending on these parameters. The relationship between frost heaving strain $\left(h^{\mathrm{p}}\right)$ and pressure transmitted to the soil $(P)$ was established. The type of this dependence obtained for a columnar foundation with a soil freezing depth of 128 $\mathrm{cm}$ is shown in Figure 3.

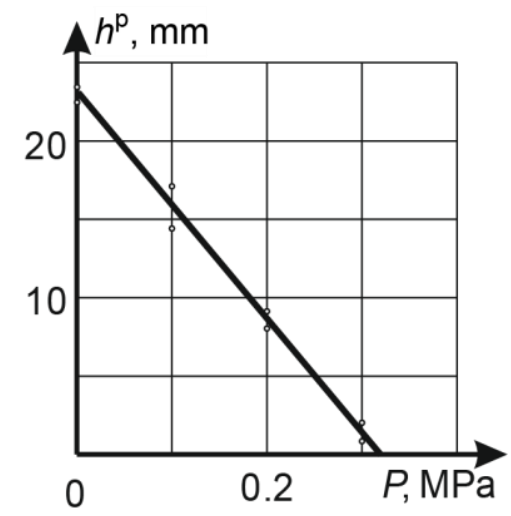

Fig. 3. Relationship between frost heaving strain and pressure transmitted to the ground.

This figure shows that normal forces of frost heaving of soil, and hence its deformation, are compensated by pressure from the external load of $0.32 \mathrm{MPa}$. The established dependence also allows us to calculate the deformation of frost heaving at lower pressures under the foundation sole depending on external loads.

Long-term experimental and theoretical studies of the interaction of low-deepened foundations with seasonally freezing soils were carried out at St. Petersburg State University of Architecture and Civil Engineering (SPbGASU) by V.D. Karlov. The results of this work served as a basis for creation a territorial methodological document "Methodology for assessing the characteristics of the frost-hazardous properties of soils in the construction of St. Petersburg TMD 50-601-2004" [9].

This document uses the indirect technique using formulas to determine soil frost hazard indicators, including the maximum normal frost heave strength. The initial data for determining these indicators are the physical and mechanical properties of soil, which are established during standard engineering and geological tests. This document provides a numerical example of characterizing the frost hazardous properties of clay soil. The initial data adopted in the example are the following: type of soil is loam, soil density is $2 \mathrm{~g} / \mathrm{cm}^{3}$, humidity is 0.25 , humidity at the boundary of flow and rolling is 0.30 and 0.15 , index of liquidity is 0.67 , plasticity number is 0.15 , dry unit weight is $1.6 \mathrm{~g} / \mathrm{cm}^{3}$, freezing depth is $1.2 \mathrm{~m}$, the maximum specific normal pressure of frost heaving determined by calculation was $0.94 \mathrm{MPa}$. The document also uses the dependence 
obtained by the authors of [8] and shown in Figure 5 there.

The recent studies in this field showed that maximum specific forces of frost heaving are in the range from 0.3 to $1 \mathrm{MPa}$ or more. The height of road structure, which creates a load on the freezing layer, most often does not exceed $1.5 \mathrm{~m}$. Obviously, this load will be less than the specific forces of frost heaving. So, the coefficient $K_{\text {nagr }}$ can also be ignored.

For testing, it is necessary to use soil samples having particle size distribution and compaction degree similar to that of soil in natural conditions. For subgrade construction the soil compaction coefficient is from 0.95 to 0.98 , depending on the category of road. Since standard laboratory tests ensure modeling of the field conditions with the necessary accuracy, it is also impractical to use coefficients $K_{\mathrm{pl}}$ and $K_{\mathrm{gr}}$.

Thus, when using standard tests to determine the degree of soil heaving in the normative methodology for calculating road pavement for frost resistance, it is possible to exclude the coefficients $K_{\text {ugv }}, K_{\mathrm{pl}}, K_{\mathrm{gr}}, K_{\text {nagr, }}$ $K_{\mathrm{vl}}$. However, it should be noted that laboratory tests should be carried out with full water saturation of samples, as follows from the works of V.I. Fedorov, and the soil compaction coefficient of the samples should correspond to the field conditions.

Based on the foregoing, we can draw the following conclusions:

1. The soil group according to the degree of heaving should be established only according to laboratory tests. The usage of indirect method for these purposes does not provide the necessary reliability when calculating the road structure for frost resistance.

2. Laboratory tests to determine the degree of soil heaving should be carried out with full water saturation of samples, and their compaction coefficient should correspond to the field conditions. It is not advisable to use coefficients $K_{\mathrm{ugv}}, K_{\mathrm{pl}}, K_{\mathrm{gr}}, K_{\mathrm{nagr}}, K_{\mathrm{vl}}$.

\section{References}

[1] Industry Road Codes ODN 218.046-01 218.04601, Designing of non-rigid pavement, Introduced 20.12.2000, Moscow: Informavtodor, 144 (2001).

[2] V.V. Lopashuk, I.N. Pugachev, A.M. Kulizhnikov, A.I. Yarmolinsky, Ed. A.M. Kulizhnikova, Restriction for motion of vehicles on the roads of the Russian Federation in the spring, Vladivostok: Dalnauka, 176 (2009).

[3] VSN 46-83, Industry-Specific Construction Standards. Instructions for the design of pavements of non-rigid type, Approved by the USSR Ministry of Transport Construction 29.04.1983, Moscow: Transport, 157 (1985). (Inoperative)

[4] The Russian State Standard GOST 25100-2011, Soils, Classification, Instead of GOST 25100-95; introduced 12.08.2011, Moscow: Standartinform, 37 (2013).

[5] The Russian State Standard GOST 28622-2012, Soils, Laboratory method for determining the degree of heaving, introduced 12.18.2012, Moscow: Standartinform, 9 (2013).

[6] V.I. Fedorov, Moisture accumulation processes and frost hazard of soils in construction, Vladivostok: DalNIIIS, 178 (1993).

[7] V.I. Fedorov, Active protection of structures and foundations in irrigated heaving hazardous soils, Vladivostok: Dalpress, 156 (1995).

[8] V.S. Sazhin, V .Ya. Shishkin, A.S. Volokh, Design and construction of structures foundations on heaving soils, Saratov: Saratov University Publishing House, 235 (1988). 